This paper is published in the open archive of Mid Sweden University

DIVA http://miun.diva-portal.org

with permission of the publisher

Citation for the peer-reviewed published paper:

Friman L, Höglund H, Högberg H, Agnemo R. Tannin-iron impregnated thermomechanical pulp : Part I: Effects of extractions and heat on brightness. Nordic Pulp \& Paper Research Journal. 2004;19(2):229-236.

URL to article at publishers site:

http://dx.doi.org/10.3183/NPPRJ-2004-19-02-p229-236 


\section{Tannin-iron impregnated thermomechanical pulp. Part l: Effects of extractions and heat on brightness}

Linda Friman, Hans Höglund and Hans-Erik Högberg, Mid Sweden University, Sundsvall, Sweden, Roland Agnemo, Domsjö Fabriker, Örnsköldsvik, Sweden

KEYWORDS: Acid treatment, Brightness, Chelating agents, Colour reversion, Iron, Polyphenols, Sulphites, Tannins, Thermomechanical pulps

SUMMARY: Tannins are polyphenolic compounds found mainly in bark. When reacting with iron, they form strongly coloured complexes, which through contamination from the bark may induce a brightness decrease of mechanical pulps. Wood itself contains phenolic compounds, which can form coloured complexes with iron. We have investigated gallotannin as a model for metal-binding sites in the pulp. The behaviour of tannin-iron complexes in solution and in pulp has been studied. In aqueous solution, the tannin-iron complexes can be decolourised by the addition of diethylenetriaminepentaacetic acid (DTPA). The colour of the tannin-iron complexes was very $\mathrm{pH}$ dependent. Thus in solution, these were decolourised at low $\mathrm{pH}$ and at high $\mathrm{pH}$ the spectral characteristics were changed substantially. We have studied the effects on brightness and heatinduced brightness loss of the impregnation of thermomechanical pulp (TMP) with 30 parts per million iron (ppm i.e. $\mathrm{mg} / \mathrm{kg}$ ) either as iron or tannin-iron as well as the possibility to decrease such effects by using various solvent extractions. The tanniniron impregnation causes a decrease in ISO-brightness of approximately $3 \%$ and an increase in the light absorption coefficient $(\mathrm{k})$ by approximately $2 \mathrm{~m}^{2} / \mathrm{kg}$ at the tannin-iron absorbance maximum, $565 \mathrm{~nm}$. These effects are approximately ten times higher than those observed for the pulp only impregnated with iron. Extraction with $1 \%$ by weight of DTPA provides a way to reduce the brightness decrease induced by the tanniniron complexes and the observed decrease can be attributed to removal of iron from the pulp. Acid extraction was the most efficient way to reduce the iron content in the pulps and to decoulorise the tannin-iron impregnated pulp. However, after acid extraction of iron impregnated pulps, new chromophores were evidently formed. Addition of the reducing agent, sulphite, to extractions had no effect on the iron removal or the brightness of the impregnated pulps. The heat-induced brightness loss is not influenced by the addition of tannin-iron or iron. The brightness loss caused by heat was lower for pulps extracted with DTPA.

ADDRESSES OF THE AUTHORS: Linda Friman (linda.friman@mh.se), Hans Höglund (hans.hoglund@mh.se) and HansErik Högberg* (hans-erik.hogberg@mh.se). Department of Natural and Environmental Sciences Mid Sweden University, 85170 Sundsvall, Sweden.

Roland Agnemo (roland.agnemo@domsjoe.com) Domsjö

Fabriker, 89180 Örnsköldsvik, Sweden.

* Corresponding author.

Lignin-metal complexes have high light absorption in the visible part of their spectra and even though they are present in only minor amounts in pulp, they contribute to the colour of mechanical pulp (Yoon et al. 1999). Other phenolic compounds present in the trees, such as tannins and other extractives can also form coloured complexes

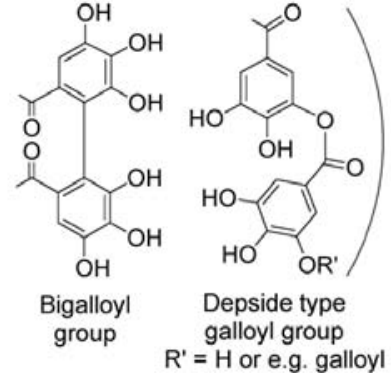

Fig 1. a) Hydrolysable tannins (see e.g. Sakai 2001).

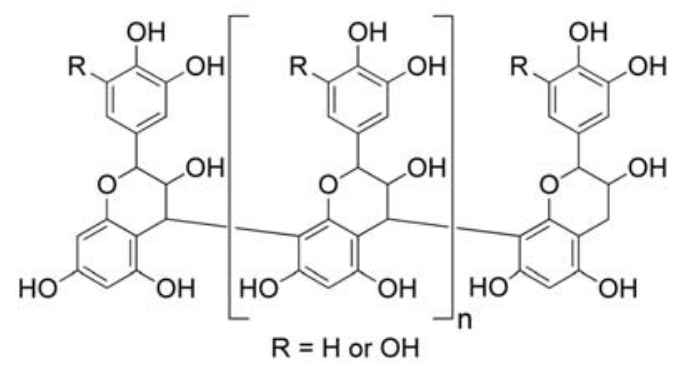

Fig 1. b) General structure of condensed tannins (see e.g. Gust, Suwalski 1994)

with metals (Ni et al. 1999; South, Miller 1998).

Tannins are often used as a common term for tannic acids, which are organic compounds of varied and complex chemical nature and are produced by many plants. They are classified into hydrolysable and condensed tannins (Fig 1). Hydrolysable tannins (Fig la), which give gallic acid on hydrolysis, are referred to as gallotannins, while those affording ellagic acid, are referred to as ellagitannins (Sakai 2001). Condensed tannins are found in many plants and are polymers of flavanoids (Fig 1 b). In spruce they occur mainly in the bark (Ullevålseter 1965).

Tannins are strong complexing agents for metal ions, such as $\mathrm{Fe}^{3+}$ and $\mathrm{Al}^{3+}$. The phenolic hydroxyl groups present in the tannins are vital sites for chelation with metal ions. The $o$-dihydroxyphenyl groups of B-rings in condensed tannin are the main ligating sites (Fig 1; Yoneda, Nakatsubo 1998). At low concentration (particularly in $0.4 \%$ aqueous solutions) $\mathrm{Fe}^{3+}$ chelated with tannins produces an intense blue colour for hydrolysable tannins and a green one for condensed tannins. At higher concentrations solutions containing tannins and $\mathrm{Fe}^{3+}$ generate a blue-black precipitate (Tonello et al. 1997).

Tannins form mixtures of mono- and bis-type complex with $\mathrm{Fe}^{3+}$ within a $\mathrm{pH}$ range of 1 to 7 , but they may also form tris-complexes (Fig 2; Gust, Suwalski 1994).

Norway Spruce (Picea abies) is a major raw material for mechanical pulp in Scandinavia. Condensed tannins are found in high concentration in bark of the Pinaceae 
<smiles>COc1c(O)cc(P)cc1C(=O)O[I-]</smiles>

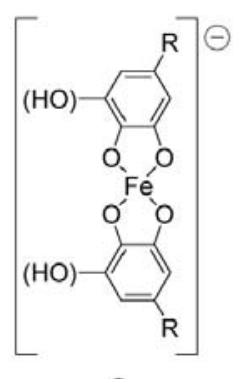

c
O)

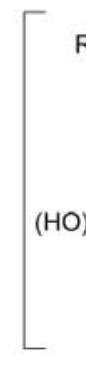
$3 \ominus$ Experimental

Fig 2. Polyphenol-iron complexes: a and b: mono-complexes (a catecholate mode, b salicylate mode); c tannin-iron bis-complexes; d tannin-iron tris-complexes. $R=$ residual part of the tannin (see e.g. Gust, Suwalski 1994). Additional water or hydroxy ligands filling the hexacoordinated binding sphere of iron are not shown.

family e.g. spruce and pine. Spruce bark normally contains approximately $10 \%$ of tannins, but the content varies between 6-20\% (Ullevålseter 1965). Compared with wood, bark contains about 5-10 times higher concentration of iron (Young, Guinn 1966).

Pulpwood can become contaminated with tannins in two different ways, either during storage by penetration into the wood from the surrounding inner bark of logs both on land and in water (Ullevålseter 1965; Persson et al. 2002) or through inefficient bark removal prior to pulping.

During the refining process the brightness of the pulp decreases (Johansson, Gellerstedt 2000). One possible reason for this is that heat increases the rate of oxidation of lignin catalysed by e.g. $\mathrm{Fe}^{3+}$ to yield both new chromophores and decomposition products, which may produce new highly coloured metal complexes (Gupta 1970; Yoon et al. 1999).

Chelating agents can form strong, colourless and soluble complexes with some of the harmful transition metals, which otherwise may form coloured complexes with wood components (Ghosh, Ni 1998). Therefore treatment of mechanical pulps with such agents results in increased brightness and brightness stability (van der Zee, Sierra-Alvarez 1996; McLellan et al. 1990).

As is evident from what is stated above, mechanical pulp contains many polyphenolics that may form coloured complexes with transition metals such as iron. Our objective has been to study the effects of such complexes on the brightness under conditions similar to those of preheating and refining of mechanical pulps. In this initial study we have decided to use iron as the metal and a commercially available and soluble tannin, gallotannin, as a model for wood polyphenolics capable of forming coloured complexes with transition metals. Thus we have studied pulp impregnated with a tanniniron complex and compared it with pulp impregnated with only iron(III) chloride and with untreated pulp. This paper describes the effects of such impregnations on the brightness of thermomechanical pulp (TMP). We have also studied if such effects can be reversed. Refining takes place at a relatively high temperature so we also studied how the various impregnated pulps behaved at elevated temperatures.

\section{Materials}

In a Swedish TMP mill a pulp sample made from fresh spruce wood was collected after the first refining stage. At this point in the process, the pulp had not been subjected to treatment with any added chemicals for example the chelating agent diethylenetriaminepentaacetic acid (DTPA).

The pulp sample was washed three times with deionised water at $3 \%$ pulp consistency and centrifuged at $14000 \mathrm{rpm}$ for 20 minutes using a JA-14 rotor to a pulp consistency $>40 \%$. This pulp was used as the raw material for impregnation with iron and tannin-iron and subsequent extractions.

Tannic acid (Gallotannin) was used as received from Fluka (lot 386523/122998). According to Makkar and Becker (1993) it is a mixture of tannic acids obtained from the leaves of Rhus coriaria and Rhus typhina, gallnuts of Rhus semialata, fruit pods of Caesalpinia spinosa, gallnuts of Quercus infectoria and fruits of Terminalia chebula.

\section{Solutions}

Stock solutions of $\mathrm{FeCl}_{3}$ (Riedel deHaën, $250 \mathrm{mg} / 1$, 0.92 $\mathrm{mmol} / \mathrm{l}$ ), tannin (Fluka, $3 \mathrm{~g} / \mathrm{l}, 1.76 \mathrm{mmol} / \mathrm{l}$ ), DTPA (Fluka, $0.5 \mathrm{~g} / \mathrm{l}, 1.27 \mathrm{mmol} / \mathrm{l}$ ) and sodium sulphite (Sigma-Aldrich, $1 \mathrm{~g} / 1,10.2 \mathrm{mmol} / \mathrm{l}$ ) were prepared in milli-Q deionised water. Impregnation solutions of $\mathrm{FeCl}_{3}$ (42.1 $\mu \mathrm{mol} / \mathrm{l})$ and tannin $(84.2 \mu \mathrm{mol} / \mathrm{l})$ were prepared through dilution of the stock solutions. The tannin-iron impregnation solution was prepared by mixing suitable volumes of the stock solutions of $\mathrm{FeCl}_{3}$ and tannin followed by dilution with milli-Q deionised water to the same concentrations as the impregnation solutions of $\mathrm{FeCl}_{3}$ and tannin. In order to ensure complete complexation of the $\mathrm{Fe}^{3+}$ and because the complex precipitates if the ratio is higher than approximately $1: 1$ the solution of tannin-iron complexes were always prepared using a 1:2 ratio of iron:tannin.

The formation of the tannin-iron complexes is not instantaneous so the tannin-iron solution was allowed to stand for at least 20 hours at room temperature prior to use.

The $\mathrm{pH}$ of the solutions used in the absorbance measurements was adjusted by mixing suitable volumes of each component with sodium hydroxide $(\mathrm{NaOH}$, Fluka) or sulphuric acid $\left(\mathrm{H}_{2} \mathrm{SO}_{4}\right.$, Riedel deHaën) and milli-Q deionised water to attain the desired initial $\mathrm{pH}$ and concentration, as specified in the legends to the figures. All measurements were performed at room temperature.

\section{Impregnation}

The pulp was mixed three minutes at a pulp consistency of $3.0 \%$ with $\mathrm{FeCl}_{3}(25.3 \mu \mathrm{mol} / \mathrm{l})$ or tannin-iron (42.1 $\mu \mathrm{mol}$ iron/l) solution. Deionised water was added until a pulp consistency of $1.5 \%$ was reached. After mixing the pulp suspension for six minutes, four sheets were prepared from a pulp with a consistency of $\sim 20 \%$ using a sheet former. The sheets were pressed and then dried in a 
climate controlled room $\left(23^{\circ} \mathrm{C}, 50 \%\right.$ relative humidity $)$ for approximately 24 hours without exposure to light.

\section{Extractions}

Extraction method 1:

The solutions used for the extraction were prepared by dilution of the stock solutions to the following concentrations: DTPA (191 $\mu \mathrm{mol} / 1,1 \% /$ oven dried (o.d.) pulp), sulphite (765 $\mu \mathrm{mol} / 1,1 \% / \mathrm{o} . d$. pulp), sulphite and DTPA (1\%/o.d. pulp of both). The $\mathrm{pH}$ was adjusted to 5.6-5.8 using $\mathrm{NaOH}(0.1 \mathrm{M})$ or $\mathrm{H}_{2} \mathrm{SO}_{4}(1 \%$ by weight $)$. The resulting solution was heated to $60^{\circ} \mathrm{C}$. Then it was mixed with the pulp for 6 minutes at a pulp consistency of $0.75 \%$. After dilution with deionised water to a pulp consistency of $0.075 \%$, it was dewatered to a pulp consistency of $20 \%$ and extracted with deionised water $\left(60^{\circ} \mathrm{C}\right)$ in the same way, the exception being that the slurry was mixed for three minutes instead of six minutes. The water extraction was repeated twice to ensure maximal removal of iron. The pulp suspension was then diluted with deionised water to a pulp consistency of $0.02 \%$ and four sheets were prepared which were pressed and then dried in a climate controlled room $\left(23^{\circ} \mathrm{C}, 50 \%\right.$ relative humidity) for approximately 24 hours without exposure to light.

An acid extraction (pH 2) of the pulp was also carried out using sulphuric acid and deionised water. The acid extraction was performed in the same way as that described above; with the exception that the deionised water used to reduce the pulp consistency was brought to pH 2 using concentrated sulphuric acid.

The final $\mathrm{pH}$ of the last water extraction cycle was 5.7-5.8. Extraction method 2:

The extraction sequence was performed in the same way as described for method 1, except that after the last water extraction an additional extraction with a solution of either DTPA, sulphite or DTPA and sulphite was carried out in the same way as that described above.

\section{Metal analyses}

Prior to the metal analyses, ashing of samples was performed according to our previously published method (Friman et al. 2003).

The samples were analysed for iron content using inductively coupled plasma optical emission spectrometry (ICP-OES) using a Thermo Jarrel Ash, Iris Advantage instrument.

At least three separately ashed samples from each pulp (or sheets made from it) were analysed and the mean value was calculated.

The metal content is reported as parts per million [ppm (i.e. $\mathrm{mg} / \mathrm{kg}$ o.d. pulp)].

\section{UV-Vis spectra and brightness measurements}

Ultraviolet-visible (UV-Vis) spectra were recorded using a Varian Cary 100 Bio UV-Visible spectrophotometer.

For liquid samples a quarts cuvette with a width of 1.0 $\mathrm{cm}$ was used and the spectra are given as absorbance $\mathrm{A}=\mathrm{f}(\lambda)$ where $\lambda$ is the wavelength in $\mathrm{nm}$ [Absorbance $(A)$ is dimensionless and can vary between zero (all light passes through the solution) and infinity (all light absorbed) and $\mathrm{A}=\mathrm{a} \cdot \mathrm{l} \cdot \mathrm{c}$ (where a is the absorbtivity $(\mathrm{L} / \mathrm{cm} \cdot \mathrm{g}$ ), $l$ is the path length $(\mathrm{cm})$ and $\mathrm{c}$ is the concentration $(\mathrm{g} / \mathrm{L})]$.

For paper samples a DRA-CA-301 accessory with a 70-mm diameter-integrating sphere coated with Spectralon ${ }^{\circledR}$ was used. The sheets had a grammage of approximately $40 \mathrm{~g} / \mathrm{m}^{2}$. Three measurements were made on each sheet and the result from each sample was an average value from at least three sheets, except for the "hotshot" treated samples (see below) where three measurements on one sheet of each sample were made.

Light absorption coefficient $(\mathrm{k})$ and the light scattering coefficient (s) were calculated from the measured reflectance over two different backgrounds, a white and a black background, according to the Kubelka-Munk theory as described by Johansson and Gellerstedt (2000). The spectra are more informative when presented as difference spectra $\Delta \mathrm{k}$ vs. $\lambda$. The $\Delta \mathrm{k}$-value is specified in each case e.g.: $\left.\Delta \mathrm{k}_{\lambda}\right)=\mathrm{k}$ (treated pulp) - $\mathrm{k}$ (untreated pulp).

The ISO-brightness of the paper samples was measured with Elrepho 2000 Datacolor.

\section{Heat-induced brightness loss}

Samples were exposed to heated steam in a so called "hotshot" equipment for 10 seconds and at four different temperatures $\left(130,150,160\right.$ and $\left.170^{\circ} \mathrm{C}\right)$. The hotshot is an apparatus developed by Koskinen et al. (1997) for the study of the influence of moisture and heat on the brightness of sheets or wood chips at high temperatures for very short periods of time. Steam is used to heat the sample at a defined temperature and for a predetermined period of time. The treatment is then interrupted rapidly by cooling with water.

In addition samples were exposed to heat at $150^{\circ} \mathrm{C}$ for $2.5,5,10,30$ and 180 minutes, respectively, under dry conditions in an oven.

\section{Results and Discussion}

\section{Abbreviations:}

Pulps:

R-pulp: Reference pulp, no impregnation.

TFe-pulp: Pulp containing $\sim 30 \mathrm{ppm}$ iron after impregnation with a tannin-iron solution.

Fe-pulp: Pulp containing $~ 30$ ppm iron after impregnation with a $\mathrm{FeCl}_{3}$ solution.

Extractions:

U: No extraction.

W: Extraction with water.

DTPA: Extraction with a DTPA solution.

Si: Extraction with a sodium sulphite solution.

A: Extraction with a sulphuric acid solution of $\mathrm{pH} 2$.

\section{Absorbance characteristics of the tannin-iron solutions} A variety of catechols and $\mathrm{Fe}^{3+}$ form complexes with broad absorption curves and with maxima $(\lambda$-max $)$ in the region 550-580 $\mathrm{nm}$ (Imsgard et al. 1971). $\mathrm{Fe}^{3+}$ complexes formed with tannic acid also show a broad absorption curve with $\lambda$-max around $560 \mathrm{~nm}$ (South, Miller 1998). 


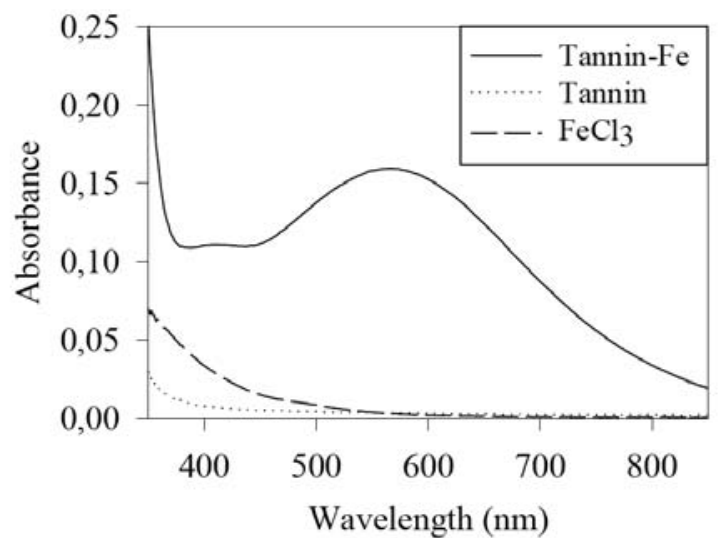

Fig 3. UV-Vis spectra of tannin, $\mathrm{FeCl}_{3}$ and tannin-iron solutions (84 $\mu \mathrm{M}$ tannin, $42 \mu \mathrm{M}$ iron, $\mathrm{pH} 4)$.

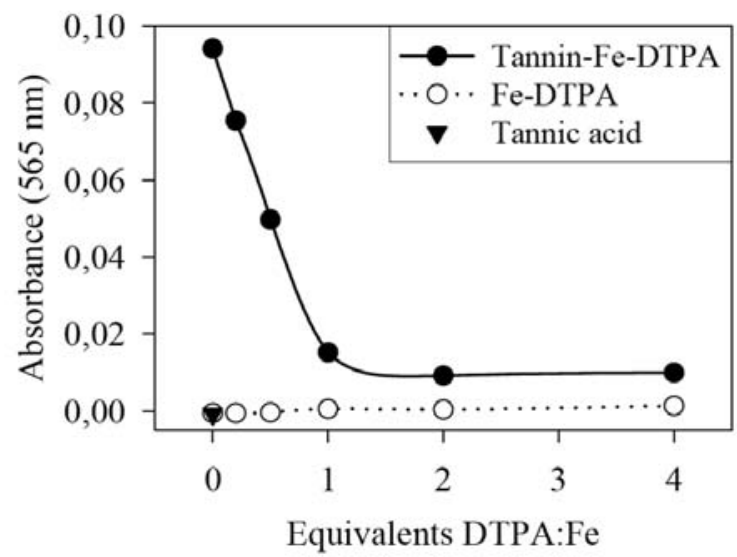

Fig 4. Absorbance at $565 \mathrm{~nm}$ of solutions of tannin-iron, iron and tannin (42 $\mu \mathrm{M}$ tannin, $21 \mu \mathrm{M}$ iron, $\mathrm{pH}$ 5.5-6.0) versus added molar equivalents of DTPA.

Fig 3 shows spectra of our impregnating solutions of tannin, $\mathrm{FeCl}_{3}$, and tannin-iron. Whereas the solutions containing either tannin or $\mathrm{FeCl}_{3}$ had low absorbance in the visible region, the presence of $\mathrm{Fe}^{3+}$ in the tannin solution caused a significant increase in the absorbance with $\lambda$-max at $\sim 565 \mathrm{~nm}$ in this region. Thus, our impregnation solution clearly contained the desired tannin-iron complexes.

The absorbance of the tannin-iron solutions was increased with increased iron:tannin-ratio according to the equation: $\mathrm{y}=0.38 \mathrm{x}\left(\mathrm{r}^{2}=0.99\right)$ at $42 \mu \mathrm{M}$ iron, $\mathrm{pH} 5$ (where $\mathrm{y}$ is the absorbance at $565 \mathrm{~nm}$ and $\mathrm{x}$ is the molar ratio of iron:tannin). In some instances, if the iron:tanninratio was higher than $1: 1$, a precipitate formed so solutions with much higher ratios could not be investigated.

\section{Influence of DTPA-treatment on the tannin-iron solutions}

Some lignin models with an isolated phenolic group and $\mathrm{Fe}^{3+}$ form complexes of rather low stability (Guillon et al. 2001). In contrast the bidentate ligand catechol forms much stronger complexes with iron and for $\mathrm{Fe}^{3+}$-catechol and $\mathrm{Fe}^{2+}$-catechol complexes the stability constants are $10^{13.9}$ and $10^{7.95}$, respectively ( $\mathrm{Ni}$ et al. 1998). To prevent iron from binding to tannins, various complexing agents have been screened as ligands and ethylenediaminetetraacetic acid (EDTA) is a very efficient one with very high

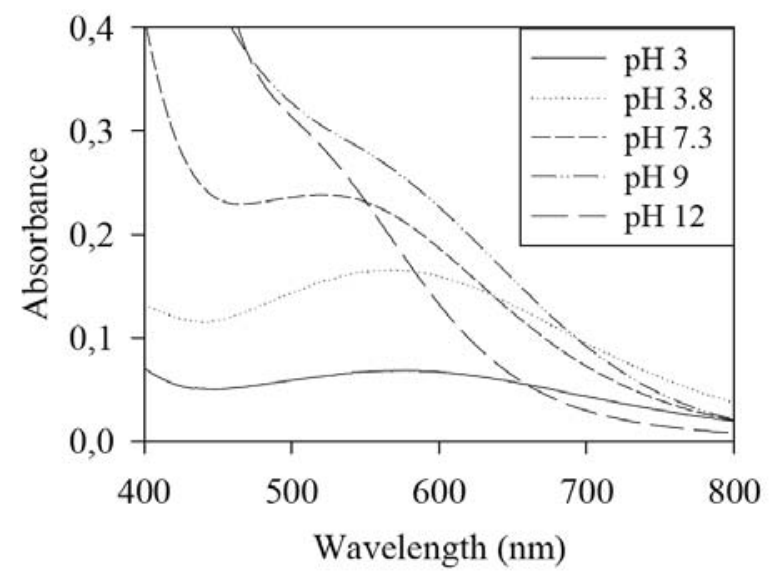

Fig 5. UV-Vis spectra of solutions of tannin-iron (84 $\mu \mathrm{M}$ tannin, 42 $\mu \mathrm{M}$ iron) at various $\mathrm{pH}$, six days after preparation.

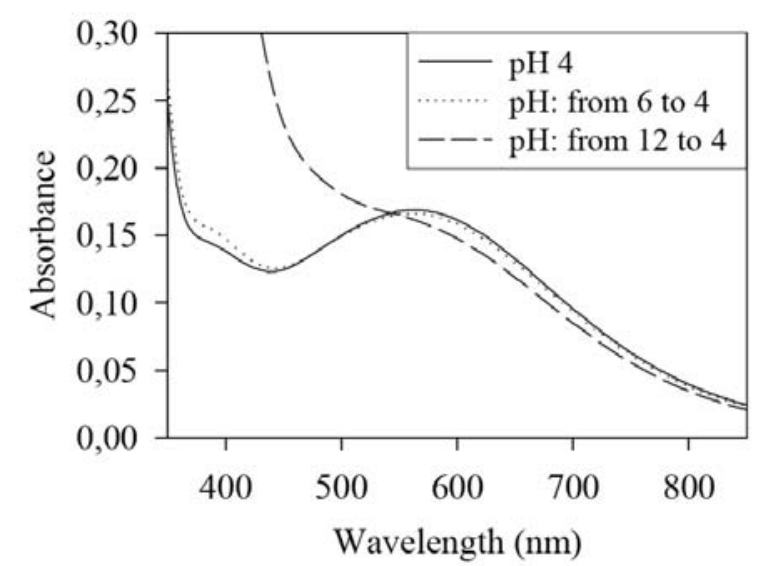

Fig 6. UV-Vis spectra of solutions of tannin-iron (84 $\mu \mathrm{M}$ tannin, 42 $\mu \mathrm{M}$ iron) at $\mathrm{pH} 4$, after $\mathrm{pH}$ adjustment from $\mathrm{pH} 4$ to $\mathrm{pH} 6$ and back to $\mathrm{pH} 4$ and from $\mathrm{pH} 4$ to $\mathrm{pH} 12$ and back to $\mathrm{pH} 4$.

affinity for iron, thus removing the latter from complexes with tannins (South, Miller 1998). In the presence of catechol and quercetin, a similar behaviour has been observed for the metal ions $\mathrm{Fe}^{3+}, \mathrm{Cu}^{2+}, \mathrm{Mn}^{2+}$ and $\mathrm{Al}^{3+}$ (Ghosh, Ni 1998; Ni et al. 1999). Compared with complexes of iron ions with catechols, the stability constant of the DTPA-Fe ${ }^{3+}$ complex is higher $\left[10^{28.6}\right.$ with a coordination stoichiometry of 1:1 DTPA:iron (The Dow Chemical Co)]. Thus DTPA should be expected to displace tannin from tannin-iron complexes. In order to confirm this, we added various molar equivalents (ranging from 0.2 to 4 ) of DTPA to a tannin-iron solution. Indeed, as the amount of DTPA was increased, the absorbance in the visible region decreased until the DTPA:iron molar ratio was approximately 1:1 (Fig 4). Because the difference in absorption spectra of the final $\mathrm{Fe}^{3+}$-DTPA and tannin-Fe ${ }^{3+}$-DTPA solutions was small, most of the iron present in the latter mixture were bound in a DTPA complex rather than in a tannin one (Fig 4).

\section{Influence of $\mathrm{pH}$ on the tannin-iron solutions}

Polyphenolic compounds complexed to metals are sensitive to $\mathrm{pH}$ variations. For example, $\mathrm{Fe}^{3+}$-phenol complexes are discoloured at low $\mathrm{pH}$ (Gore, Newman 1964). Therefore we studied the effect of variations of $\mathrm{pH}$ on the UV-visible spectra of our tannin-iron solutions.

When we lowered the $\mathrm{pH}$-value from a neutral to an 
acidic one, the absorbance of the tannin-iron solution was decreased especially in the $\mathrm{pH}$ range from 3.8 to 3 . As discussed above, the most important iron-ligating groups in the gallotannins are the phenolic groups. Although the $\mathrm{pK}_{\mathrm{a}}$-values of these will be over 7 in a monomeric gallic ester, in a polymeric structure such as that of gallotannin the first $\mathrm{pK}_{\mathrm{a}}$-value (out of 15) of this will be expected to be much lower. Therefore the observed decrease in absorbance was probably due to the competition between protons and iron ions for the complexing sites in tannin, resulting in decreased ligation of the $\mathrm{Fe}^{3+}$ and/or the liberation of free hydrated $\mathrm{Fe}^{3+}$-ions. The $\mathrm{pK}_{\mathrm{a}}$-values for various lignin models containing carboxylic acids have $\mathrm{pK}_{\mathrm{a}}$-values in the range 4.0-4.5 (Guillon et al. 2001). Therefore, protonation of scattered iron-ligated carboxylate groups present in the structurally complex tanniniron could also contribute to the $\mathrm{pH}$-effect we observed.

Increasing the $\mathrm{pH}$ from a neutral to an alkaline one will affect tannin-iron complexes in several ways. First, a $\mathrm{pH}$ increase leads to precipitation of iron as insoluble hydroxides with formation of free tannins and hence lowered absorbance. Second, alkaline hydrolytic breakdown of tannins affords free glucose and gallates and hence changed absorbance. Third, phenolate ions, formed from tannins at high $\mathrm{pH}$, are very sensitive to oxidation especially in the presence of an oxidant like $\mathrm{Fe}^{3+}$. Indeed, Tonello et al. (1997) have observed that in order to prevent oxidation reactions of tannins, the $\mathrm{pH}$ must be lower than 6 . We found that if the $\mathrm{pH}$ of a tanniniron solution was increased, the original peak from the tannin-iron complexes had either disappeared or was hidden under an increased absorption in the 400-600 nm region (Fig 5). Probably irreversible reactions had occurred. Indeed, when $\mathrm{pH}$ of a tannin-iron solution was raised from $\mathrm{pH} 4$ to $\mathrm{pH} 12$ and left for 8 days followed by readjusting it to $\mathrm{pH} 4$, the absorbance had changed significantly probably due to irreversible formation of quinoid structures (Fig 6).

\section{Removal of iron from impregnated pulp}

Having established the properties of the tannin-iron impregnation solutions, we turned our attention to the problem of removing iron from the pulp. The efficiency of the iron removal from the pulp impregnated with either tannin-iron complexes or $\mathrm{Fe}^{3+}$ ions varies according to the extraction methods used and increases in the following order: Si and W $<$ DTPA+Si and DTPA $<$ A (Fig 7). There was no significant difference in the efficiency of iron removal between the iron and tannin-iron impregnated pulps, but the iron impregnated pulp is not shown in Fig 7 because it had no influence on the brightness decrease.

$\mathrm{Fe}^{3+}$ has a higher stability constant for phenols than $\mathrm{Fe}^{2+}$ (see above). Therefore removal of iron should be facilitated under reducing conditions. Indeed $\mathrm{Ni}$ et al. (1998) have shown that if a reducing agent such as sulphite or borohydride, is present in the DTPA extraction step, removal of transition metals e.g. iron from mechanical pulps is facilitated leading to a brightness gain during the subsequent peroxide bleaching step.

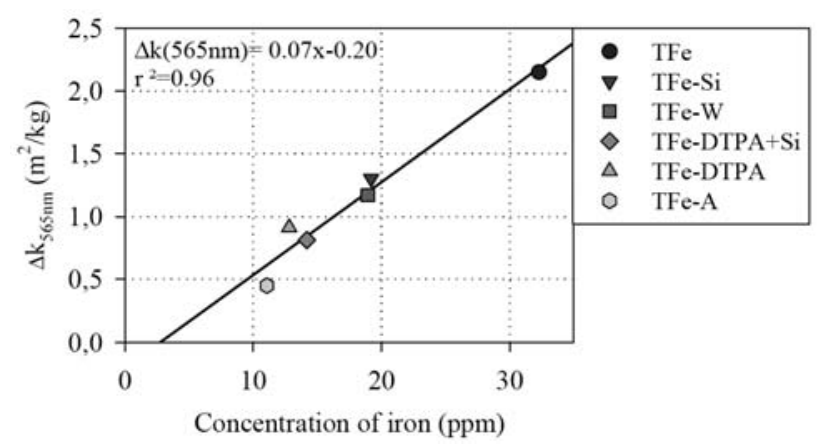

Fig 7. The $\Delta \mathrm{k}$-value at $565 \mathrm{~nm}[\Delta \mathrm{k}=\mathrm{k}$ (extracted impregnated) $\mathrm{k}$ (extracted reference)] versus the iron levels of tannin-iron impregnated pulp after various extractions according to method 2. Abbreviations are explained in the text

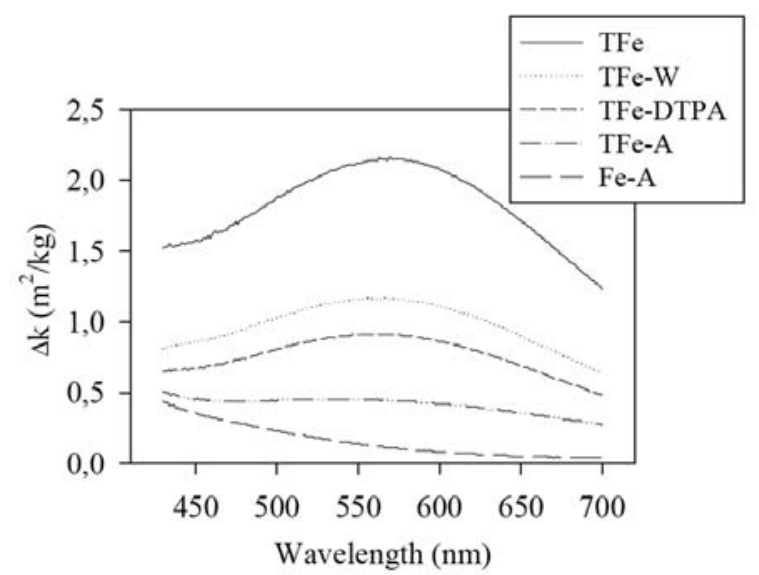

Fig 8. Visible spectra of sheets from tannin-iron impregnated pulps extracted according to method 2. $\Delta \mathrm{k}=\mathrm{k}$ (extracted impregnated) $\mathrm{k}$ (extracted reference). Abbreviations are explained in the text

However, for the tannin-iron and iron impregnated pulps we prepared, the iron-levels were essentially the same whether they were extracted with DTPA alone or with DTPA-sulphite (Fig 7).

The reference pulp samples $(\mathbf{R})$ contained 1-5 ppm iron.

\section{Brightness}

Mechanical pulps with a high content of bark and hence a high content of tannin have a reduced brightness. A study by Lorås (1976) on spruce chips shows that the presence of $1 \%$ and $3 \%$ by weight of bark in unbleached thermomechanical pulp increases the light absorption coefficient (k) by approximately 2 and $6 \mathrm{~m}^{2} / \mathrm{kg}$, respectively.

The pulp impregnated with tannin-iron complexes (TFe-pulp) displayed a significantly decreased brightness $\left(\Delta \mathrm{k}_{565 \mathrm{~nm}}=\mathrm{k}(\mathbf{T F e})-\mathrm{k}(\mathbf{R})=2.2 \mathrm{~m}^{2} / \mathrm{kg}\right)$ compared with that measured for the pulp impregnated with iron only $\left(\Delta \mathrm{k}_{565 \mathrm{~nm}}=0.22 \mathrm{~m}^{2} / \mathrm{kg}\right)$.

Depending on the amount of tannin-iron (17-42 ppm iron) in the TFe-pulp, the k-value increased linearly, from 1.0 to $2.7 \mathrm{~m}^{2} / \mathrm{kg}$ according to the equation: $\mathrm{k}_{565 \mathrm{~nm}}=0.07[\mathrm{Fe}]-0.15\left(\mathrm{r}^{2}=0.93\right)$, (where $[\mathrm{Fe}]$ is the amount of iron in ppm).

Extraction of the TFe-pulp led to different levels of brightness increase depending on the treatment. Thus the brightness increased in the following order: $\mathbf{U}<\mathbf{S i}$ and $\mathbf{W}<\mathbf{D T P A}+\mathbf{S i}$ and DTPA $<\mathbf{A}$. This was the same order as that observed above for the efficiency of iron-removal from the TFe-pulp discussed above and it clearly 
demonstrates that a decreased amount of iron in the pulp resulted in increased brightness (Fig 7 and Fig 8).

When extracted with water or sulphite ( $\mathbf{W}$ or $\mathbf{S i})$, the TFe-pulp displayed a lower $\Delta \mathrm{k}$-value $\left(\sim-1 \mathrm{~m}^{2} / \mathrm{kg}\right)$. This was probably due to the lower iron content, which in this case had decreased to approximately 20 ppm (Fig 7).

After extraction with DTPA or a combination of DTPA and sulphite, the TFe-pulp also showed a lower $\Delta \mathrm{k}$-value $\left(\sim-1.5 \mathrm{~m}^{2} / \mathrm{kg}\right)$. As discussed above, DTPA is able to extract some of the iron from the untreated TFe-pulp. Therefore a decreased iron content in the extracted pulp could be responsible for a large part of the observed brightness increase. However, as evidenced by the residual absorbance at $565 \mathrm{~nm}$ of the TFe-pulp after DTPA-extraction (DTPA:iron molar ratio $>40$ ), the latter failed to completely remove the tannin-iron complexes from the TFe-pulp (Fig 8). Probably the accessibility of the tannin-iron complexes in the pulp was too low.

When extracted with acid, the TFe-pulp displayed a decrease of $\Delta \mathrm{k}$-value of almost $-2 \mathrm{~m}^{2} / \mathrm{kg}$, and the characteristic peak at $565 \mathrm{~nm}$ of the tannin-iron complexes had almost disappeared (Fig 8). This was probably due to the competition between the protons and iron ions for the tannin ligating sites, resulting in freely soluble iron ions and colourless iron-free tannins.

When impregnating the R-pulp with iron we observed only a small decrease in brightness. This decrease is probably due to either formation of coloured complexes with phenolic groups in the pulp or oxidation of these to give coloured chromophores. The $\Delta \mathrm{k}$-values of all the extracted/unextracted iron impregnated pulps were very similar, except for the acid extracted (A) Fe-pulp, which had the highest $\Delta \mathrm{k}$-values, especially at lower wavelengths $(\sim 430-530 \mathrm{~nm})$. Acid induced chromophore formation can be responsible for this.

The acid extracted TFe- and Fe-pulps had almost the same $\Delta \mathrm{k}$-values in particular at lower wavelengths, which indicated that the tannin-iron complexes in the former were partly decomposed, while a simultaneous acid induced chromophore formation occurred (Fig 8).

Read et al. (1968) have shown that addition of 200-350 ppm iron to groundwood pulp reduces the brightness by 2 to 3 ISO-\%, which may be due to formation of coloured iron complexes. The addition of $10 \mathrm{ppm}$ and $100 \mathrm{ppm}$ $\mathrm{Fe}^{3+}$ to TMP causes a brightness loss of 1-2 and 4-5 ISO$\%$ respectively while addition of $0.2 \%$ EDTA to the iron impregnated pulps is sufficient for improving the brightness with up to 5 ISO-\% (van der Zee, SierraAlvarez 1996). Contrary to their results we found that the ISO-brightness of the reference pulp $(\mathbf{R})$ and the ironimpregnated pulp $(\mathbf{F e})$ had the same ISO-brightness value, around 63 . As both pulps had the same brightness, no effect of extraction with DTPA was noted. The pulp impregnated with tannin-iron complexes (TFe-pulp) had a brightness which was 3 ISO-\% lower than that for the reference pulp. However, when the pulps had been extracted, the difference became smaller. This was particularly striking after acid extraction (Fig 9).

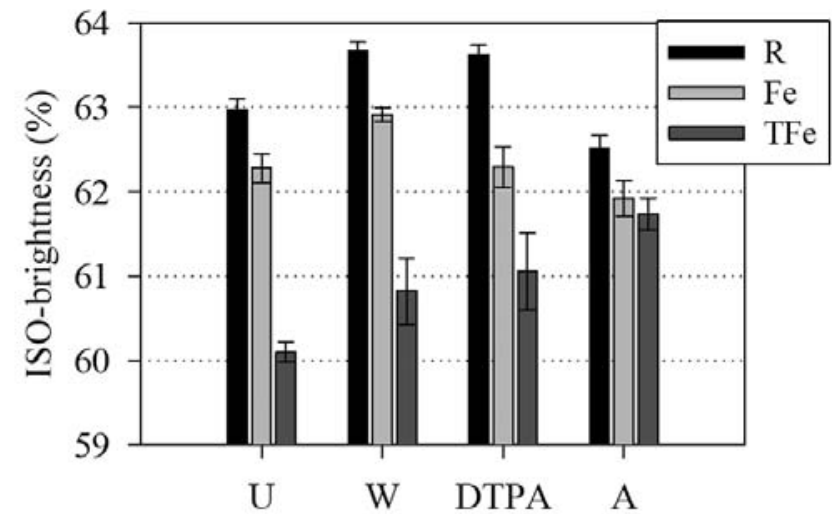

Fig 9. The ISO-brightness (\%) of sheets from various pulps before and after various extractions according to method 2. Abbreviations are explained in the text. The mean value and standard deviation is calculated from three measurements on each sheet from at least four replicates on each treated pulp.

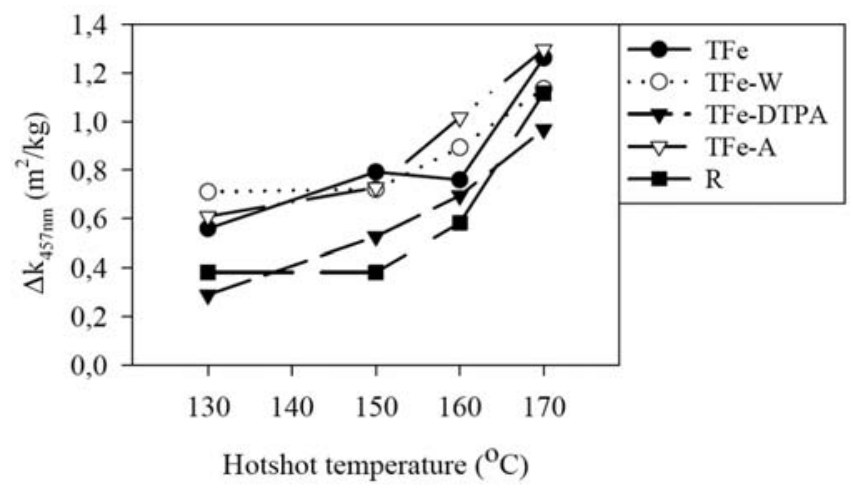

Fig 10. The $\Delta \mathrm{k}$-values of various samples aged at different temperatures for 10 seconds in the hotshot $[\Delta \mathrm{k}=\mathrm{k}$ (aged sample) $-\mathrm{k}$ (nonaged sample)]. Abbreviations are explained in the text.

\section{Heat-induced brightness loss}

Sheets made from various pulps were exposed to superheated steam for 10 seconds in the "hotshot" equipment at $130,150,160$ and finally $170^{\circ} \mathrm{C}$. The $\Delta \mathrm{k}$-values $[(\Delta \mathrm{k}=$ $\mathrm{k}$ (heated) - $\mathrm{k}$ (not heated)] increased with increasing temperature. The $\Delta \mathrm{k}$-values for the different sheets were between $0.1-0.7 \mathrm{~m}^{2} / \mathrm{kg}$ after treatment at $130^{\circ} \mathrm{C}$ and they increased to between $0.8-1.3 \mathrm{~m}^{2} / \mathrm{kg}$ after treatment at $170^{\circ} \mathrm{C}$. Although the initial brightness was different for the various sheets, no significant differences in brightness loss after the hotshot treatment could be noted when comparing the R-, Fe- or TFe-pulps, except that the DTPA extracted samples showed a tendency for lower brightness loss (Fig 10).

In order to distinguish between the various treated pulps, sheets from these were exposed to heat for longer periods of time in an oven in a normal air atmosphere $\left(150^{\circ} \mathrm{C}\right.$ for $2.5,5,10,30$ and 180 minutes). Even when the sheets from the $\mathbf{T F e}$ - or $\mathbf{F e}$-pulp were exposed to heat at $150^{\circ} \mathrm{C}$ for three hours, we did not observe any increased brightness loss, compared with that observed for the R-pulp (Fig 11b). We therefore draw the conclusion that brightness loss due to heat exposure is not significantly affected by iron ions, whether or not they are bound as complexes. This is in contrast with earlier findings where added iron caused increased brightness loss (Gupta 1970; Read et al. 1968).

It has been claimed that, except for iron, most metals e.g. manganese, copper, and zinc have no effect on 


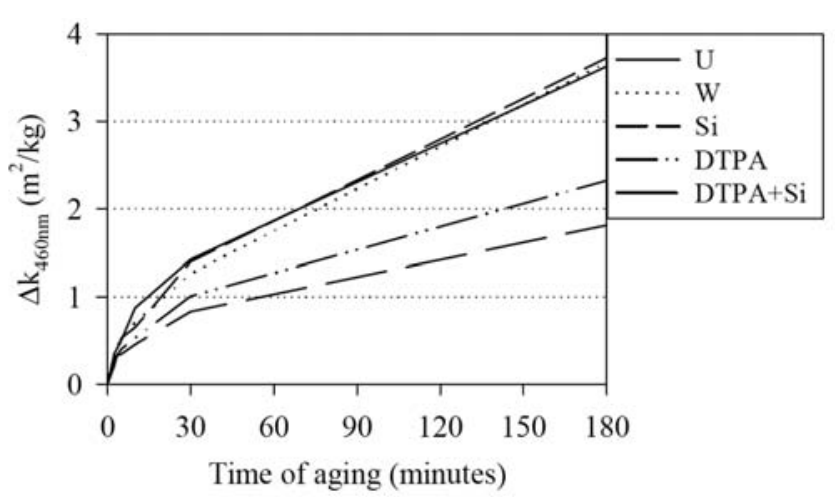

Fig 11. a) The $\Delta \mathrm{k}$ at $460 \mathrm{~nm}$ for reference sample exposed to various extractions aged at $150^{\circ} \mathrm{C}$ for different times.

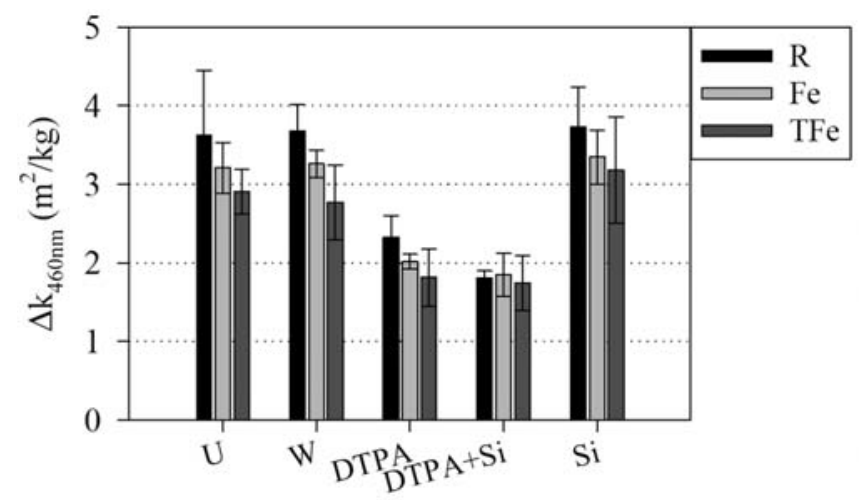

Fig 11. b) The $\Delta \mathrm{k}$ at $460 \mathrm{~nm}$ for various samples aged at $150^{\circ} \mathrm{C}$ for 180 minutes. $\Delta \mathrm{k}=\mathrm{k}$ (aged sample) $-\mathrm{k}$ (non-aged sample). Abbreviations are explained in the text. The mean value and standard deviation is calculated from three measurements on each sheet from three replicates on each treated pulp.

brightness or heat-induced brightness loss (Gupta 1970; Read et al. 1968). However, metals such as manganese and copper are known to catalyse the oxidation of hydroquinones and catechols to the corresponding quinoid structure, and these metals can be eliminated by the addition of a chelating agent (Gellerstedt, Pettersson 1980). In addition, complexes between catechol and the metals iron, copper, manganese and aluminium have been investigated and among these, iron and copper form the most highly coloured ones, which, however, can be decolourised by treatment with a chelating agent (Ghosh, Ni 1998). Addition of iron, copper, and aluminium to sheets increases the aging, but this effect could be reversed by spraying the sheets with DTPA prior to aging (Ni et al. 1997). Treatment of mechanical pulp with chelating agents is known to reduce heat-induced brightness loss (McLellan et al. 1990). We found that various pulp samples extracted with DTPA showed the lowest brightness loss (Fig 11). Although the iron-content of the DTPA extracted R-, Fe- or TFe-pulps was higher for the latter two, no significant difference in the brightness loss was noted among these pulps. This indicated that the positive effect of DTPA was not due to removal of some of the iron from the Fe- or TFe-pulps. Regarding the decrease of the investigated metals in the pulps after DTPA extraction, the manganese-content was lowered at least ten times, and to a much lower degree also the content of copper and zinc. Apart from iron, many other metals can affect the brightness and heat-induced brightness loss of mechanical pulps. Therefore, the reduced brightness loss after DTPA extraction observed by us can probably be attributed to lower contents of metals other than iron.

Gellerstedt et al. (1983) have shown that addition of a combination of sulphite and DTPA to mechanical pulps yields increased brightness stability. They suggest that the formation of quinones may be suppressed by sulphite ions and in combination with chelating agent the sulphite becomes more stable against autoxidation and its efficiency is thus increased. We found that the reference pulp extracted with a combination of DTPA and sulphite had a lower brightness loss than the DTPA extracted pulp. The heat-induced brightness loss of either Fe- or TFepulps was not suppressed by DTPA+Si extraction, probably due to iron catalysed sulphite decomposition (Fig 11).

In order to investigate if remaining extraction chemicals in the sheets had any effect on the brightness or on the heat-induced brightness loss, we added an additional extraction step with chemicals (method 2) after the last water wash in method 1 (see Experimental). Regardless of which method we used, there was no significant difference in brightness, heat-induced brightness loss, or iron content of any of the samples.

\section{Recommendations for the mechanical pulp industry}

This work has shown; that compared to an almost iron free mechanical pulp, one containing a maximum of 30 ppm iron either as $\mathrm{Fe}^{3+}$ or as tannin-iron complexes does not show significantly higher discolouration under the defibration temperature conditions.

Under the same process conditions but with prior DTPA-extraction, all these pulps showed reduced discolouration.

The consequences of these observations are, that the iron level of $30 \mathrm{ppm}$, which is normally found in wood chips before the refining stages, has no significant impact on the brightness loss that occurs in the refiner.

Impregnation of the wood chips with DTPA would have a further beneficial effect in order to prevent the discolouration of the refined pulp.

\section{Conclusions}

For thermomechanical pulp impregnated with either 30 ppm iron either as $\mathrm{Fe}^{3+}$ or as tannin-iron complexes, the brightness, heat-induced brightness loss, and the possiblity to remove iron were investigated. How various extraction processes influenced these variables, e.g. by using a reducing agent, a chelating agent, or acid was also investigated. We also studied the absorbance of iron and tannin-iron in solutions. The main findings are:

- The addition of DTPA to a tannin-iron solution reduces the absorbance in the visible region to almost zero because the strongly coloured tannin-iron complexes are converted to the less coloured and soluble DTPA-iron complexes. Although less pronounced, the same effect is seen for pulp impregnated with tannin-iron after extraction with $1 \%$ DTPA. Due to removal of iron ions by DTPA, the brightness decrease caused by tannin-iron, of the pulp can be reversed with $>50 \%$. 
induced yellowing of mechanical pulps, Svensk Papperstidn., 83:15, R157-163. Gellerstedt, G. and Pettersson, B. (1980): Autooxidation of lignin, Svensk Papperstidn., 83:11, 314-318.

- The impregnation solution containing tannin-iron complexes can be decolourised by lowering the $\mathrm{pH}$ of the solution.

- Compared to impregnation with iron only, impregnation of TMP with tannin-iron complexes yields a pulp with a much stronger colour in the visible region. Addition of $30 \mathrm{ppm}$ iron as tannin-iron complexes to TMP decreases the ISO-brightness with $3 \%$ and increases the k-value with $2 \mathrm{~m}^{2} / \mathrm{kg}$ at its absorbance maximum $565 \mathrm{~nm}$. The tannin-iron solution used for impregnation shows $\lambda$-max at the same wavelength.

- Acid extraction decreases the brightness of the iron impregnated pulp and increases the brightness of the tannin-iron impregnated pulp, yielding pulps with similar brightness. This is especially apparent at short wavelengths indicating that the tannin-iron complexes are destroyed and that new chromophores are formed probably due to the remaining iron in the pulp, which enhance the effects of the acid treatment.

- Extraction of the impregnated pulp with the reducing agent sulphite in combination with DTPA neither enhances the efficiency of removal of iron nor does it lead to increased brightness indicating that $\mathrm{Fe}^{3+}$ ions present in the pulp is not reduced to more easily removed $\mathrm{Fe}^{2+}$ ions.

- When exposed to heat, sheets from pulps impregnated with iron or tannin-iron complexes gave very similar brightness loss comparable with that observed for the untreated reference pulp. This shows that the additional iron content present in the sheets must be chemically inactive and does not affect the brightness loss. Therefore, our experiments suggest that iron removal before refining should have little influence on the brightness loss due to refining.

- Extraction of the pulps with DTPA before heat treatment decreases the brightness loss, which might be due to removal of other metals besides iron. Therefore pretreatment of the chips with DTPA prior to refining may lead to a brighter pulp.

- After heating, sheets from the reference pulp extracted with a mixture of DTPA and sulphite shows a smaller brightness loss than that observed for the ones extracted with only DTPA. The same tendency was not seen for the tannin-iron or iron impregnated pulp extracted with the combination of DTPA and sulphite.

\section{Acknowledgements}

We thank the Bo Rydin foundation and Mid Sweden University for financial support. We are also grateful to SCA Graphic Research for allowing us to use their ICP and other equipment. We thank Dr. John Kettle for his valuable comments.

\section{Literature}

Friman, L., Logenius, L., Agnemo, R. and Högberg, H.-E. (2003): Comparison of metal profiles in thermomechanical pulping processes in which either hydrogen peroxide or dithionite bleaching is used; Content of metals in process waters and in chips and pulp samples before and after extreaction with acid or a chelating agent, Paperi Puu, 85:6, 334-339.

Gellerstedt, G., Pettersson, I. and Sundin, S. (1983): Light-induced and heat-
Ghosh, A. and Ni, Y. (1998): Metal ion complexes and their relationship to pulp brightness, J. Pulp Paper Sci., 24:1, 26-31.

Gore, P.H. and Newman, P.J. (1964): Quantitative aspects of the colour reaction between iron(III) and phenols, Anal. Chim. Acta, 31, 111-120.

Guillon, E., Merdy, P.; Aplincourt, M., Dumonceau, J. and Vezin, H. (2001): Structural characterization and iron(III) binding ability of dimeric and polymeric lignin models, J. Colloid Interface Sci., 239, 39-48.

Gupta, V.N. (1970): Effect of metal ions on brightness, bleachability and colour reversion of groundwood, Pulp Paper Mag. Can., 71:18, 69-77. tion products of polyphenols and iron compounds, Corrosion, 50:5, 355-365. Imsgard, F., Falkehag, S.I. and Kringstad, K.P. (1971): On possible chromophoric structures in spruce wood, Tappi, 54:10, 1680-1684.

Johansson, M. and Gellerstedt, G. (2000): Chromophoric content in wood and mechanical pulps, Nordic Pulp Paper Res. J., 15:4, 282-285.

Koskinen, J., Salerma, M. and Forsskåhl, I. (1997): Hot-shot: rapid heat-aging of mechanical pulps, Int. Mechanical. Pulp. Conf., Stockholm, Sweden, 377-379. Lorås, V. (1976): Brightening of thermomechanical pulp, Tappi, 59:11; 99-101.

Makkar, H.P.S. and Becker, K. (1993): Behaviour of tannic acid from various commercial sources towards redox, metal complexing and protein precipitation assays of tannins, J. Sci. Food Agric. 62, 295-299.

McLellan, F., Colodette, J.L., Fairbank, M.G. and Whiting, P. (1990): Factors affecting ambient thermal reversion of high-yield pulps, J. Pulp Paper Sci., 16:6, J173-J179.

Ni, Y., Ng, A. and Mosher, M. (1999): A model compound study: The formation of colored metallic extractive complexes and their effect on the brightness of TMP pulp, J. Wood Chem. Techn., 19:3, 213-223.

Ni, Y., Li, Z., Jiang, Q., Court, G. and Burtt, M. (1998): Improved transition metal removal in a reducing agent-assisted chelation stage: a laboratory study, Pulp Paper Can., 99:8, 77-80.

Ni, Y., Li, Z. and Heiningen, A.R.P. (1997): Minimization of the brightness loss due to metal ions in process water for bleached mechanical pulps, Pulp Paper Can., 98:10, 72-75.

Persson, E., Bergquist, J., Elowson, T., Jäkärä, J. and Lönnberg, B. (2002): Brightness, bleachability and colour reversion of groundwood made of wet- and dry-stored Norway spruce (Picea abies) pulpwood, Paperi Puu, 84:6, 411-415.

Read, D.W., Eade, B.D. and Slingsby, N.R. (1968): The origin and some effects Paper Mag. Can., 63:13, 51-58.

Sakai, K. (2001) in: Wood and cellulosic chemistry, Marcel Dekker, New York Basel, Hon, D., N.-S. and Shiraishi, N. (Eds.), 256-261.

South, P.K. and Miller, D.D. (1998): Iron binding by tannic acid: effects of selected ligands, Food Chemistry, 63:2, 167-172.

The Dow Chemical Company, Keys to chelation, Forms No. 298-715-80.

Tonello, M.L., Giúdice, C.A. and Benítez, J.C. (1997): Extraction and characterisation of quebracho (schinopsis sp.) tannins, Pitture e Vernici, 73:14, 9-16.

Ullevålseter, R.0. (1965): Tanninskade på ubarket grantommer, Norsk skogsindustri, 11, 475-485.

van der Zee, M.E. and Sierra-Alvarez, R. (1996): Brightness improvement of douglas fir thermomechanical pulp by EDTA and ascorbic acid treatments on chips, J. Wood Chem. Techn., 16:2, 155-167.

Yoneda, S. and Nakatsubo, F. (1998): Effects of the hydroxylation patterns and degrees of polymerization of condesed tannins on their metal-chelating capacity, J. Wood Chem. Techn., 18:2, 193-205.

Yoon, B.-H., Wang, L.-J. and Kim, G.-S. (1999): Formation of lignin-metal complexes by photo-irradiation and their effect on colour reversion of TMP, J. Pulp Paper Sci., 25:8, 289-293.

Young, H.E. and Guinn, V.P. (1966): Chemical elements in complete mature trees of seven species in Maine, Tappi, 49:5, 190-197.

Manuscript received November 24, 2003 Accepted February 2004
Gust, J. and Suwalski, J. (1994): Use of mössbauer spectroscopy to study reacof contaminating metal ions in the groundwood bleaching environment, Pulp 